\title{
Comparative analysis of NRF2-responsive gene expression in AcPC-1 pancreatic cancer cell line
}

\author{
Yong Weon Yi $\cdot$ Seunghoon Oh
}

Received: 18 November 2014 / Accepted: 27 November 2014/Published online: 5 December 2014

(C) The Author(s) 2014. This article is published with open access at Springerlink.com

\begin{abstract}
NRF2 is a nuclear transcription factor activated in response to oxidative stress and related with metabolizing of xenotoxic materials and $\mathrm{ABC}$ transporter mediated drug resistance. We studied the expression of mRNAs under the siRNA-mediated knockdown of NRF2 and tBHQ-treated condition in AsPC-1 metastatic pancreatic cancer cell line to understand the AsPC-1 specific role(s) of NRF2 and further to investigate the relationship between drug resistance and metastatic plasticity and mobility of AsPc1. Here we show that the genes of aldo-keto reductases, cytochrome P450 family, aldehyde dehydrogenase, thioredoxin reductase, $\mathrm{ABC}$ transporter and epoxide hydrolase responsible for drug metabolism or oxidative stress concisely responded to NRF2 stabilization and knockdown of NRF2. In addition the expression of PIR, a candidate of oncogene and KISSI, a suppressor of metastasis were affected by NRF2 stabilization and knockdown. Our result provide comprehensive understanding of NRF2 target genes of drug response, oxidative stress response and metastasis in AsPc-1 metastatic pancreatic cancer cell line.
\end{abstract}

Electronic supplementary material The online version of this article (doi:10.1007/s13258-014-0253-2) contains supplementary material, which is available to authorized users.

\section{Y. W. Yi}

Department of Nanobiomedical Science, Graduate School, Dankook University, 119 Dandae-ro, Dongnam-gu, Cheonan-si, Chungnam 330-714, Republic of Korea

\section{S. Oh $(\bowtie)$}

Department of Physiology, College of Medicine, Dankook

University, 119 Dandae-ro, Dongnam-gu, Cheonan-si,

Chungnam 330-714, Republic of Korea

e-mail: seung@dku.edu
Keywords NRF2 - tBHQ - AsPC-1 - Pancreatic cancer · Oxidative stress $\cdot$ Drug metabolism

\section{Introduction}

Every cell is inevitably exposed to extracellular and intracellular oxidative stress, every moment (Finkel 2011; Ma 2010). The nuclear factor erythroid 2-related factor 2 (NRF2 or NFE2L2) is a master transcription factor that activates a battery of genes which have roles in oxidative stress responses, detoxifications, and drug resistances (Bryan et al. 2013; Ma 2013; Mitsuishi et al. 2012; Niture et al. 2014). NRF2 binds to a DNA element, named antioxidant response element (ARE), in the promoter regions of its target genes to activate transcription of these genes (Nguyen et al. 2003). The target genes of NRF2 includes (a) antioxidant genes such as $\mathrm{NAD}(\mathrm{P}) \mathrm{H}$ dehydrogenase [quinone] 1 (NQO1), heme oxygenase (decycling) 1 $(H M O X 1)$, superoxide dismutase $[\mathrm{Cu}-\mathrm{Zn}](\mathrm{SOD} 1)$, and glutamate-cysteine ligase catalytic subunit (GCLC); (b) detoxification genes including glutathione S-transferase A3 (GSTA3) and thioredoxin reductase 1, cytoplasmic (TXNRD1); (c) and drug resistance genes such as ATPbinding cassette sub-family $\mathrm{G}$ member 2 (ABCG2) and ATP-binding cassette, sub-family C (CFTR/MRP), member 5 (ABCC5) (Malhotra et al. 2010; Nguyen et al. 2003).

Reactive oxygen species (ROS), which are produced by various exogenous or endogenous sources, are double-edge swords. Under tight cellular control, ROS act as important signaling molecules to regulate diverse cellular functions including transcriptional regulation and signal transduction (Corcoran and Cotter 2013; Finkel 2011; Jennings et al. 2013; Ma 2010; Ray et al. 2012). On the contrary uncontrolled production of ROS causes various human diseases 
through DNA damage and impaired cellular functions via oxidative stress (Acharya et al. 2010; Caputo et al. 2012; Kakehashi et al. 2013; Kryston et al. 2011; Saeidnia and Abdollahi 2013; Storr et al. 2013). As an ROS sensor, the level of NRF2 is tightly regulated by a set of proteins through proteasome-dependent proteloysis. The wellknown negative regulator of NRF2 is the Kelch-like erythroid cell-derived protein with CNC homology-associated protein 1 (KEAP1). KEAP1 binds and destabilized NRF2 through ubiquitin-dependent proteasomal degradation under normal reducing condition (Bryan et al. 2013; Mitsuishi et al. 2012; Niture et al. 2014; Storr et al. 2013). NRF2 stability is also regulated by the CR6-interacting factor 1 (CRIF1) under both reducing and oxidative stress conditions (Kang et al. 2010) and the glycogen synthase kinase $3 \beta(\mathrm{GSK} 3 \beta) / \beta$-transducin repeat-containing protein ( $\beta$-TrCP) axis (Chowdhry et al. 2013; Rada et al. 2011; Rada et al. 2012). It has been reported that stability of NRF2 is also regulated by competitive protein-protein interaction to inhibit NRF2-KEAP1 binding by various proteins such as p21 (Chen et al. 2009), the Wilms tumor gene on X chromosome (WTX) (Camp et al. 2012), p62 (Komatsu et al. 2010), the partner and localizer of BRCA2 (PALB2) (Ma et al. 2012), the dipeptidyl peptidase III (DPP3) (Hast et al. 2013), and the breast cancer susceptibility gene 1 (BRCA1) (Gorrini et al. 2013).

NRF2 functions as either a protector against tumorigenesis or oncogene (DeNicola et al. 2011; Kensler and Wakabayashi 2010; Loboda et al. 2008; Muller and Hengstermann 2012). Stability and activity of NRF2 is important in human diseases, especially in cancers. While NRF2 decreases tumor susceptibility in most carcinogenesis models, constitutive activation of NRF2 may enhance tumor cell proliferation and/or confer drug resistance in lung, pancreatic as well as colorectal cancer cells (Arlt et al. 2013; Bryan et al. 2013; Duong et al. 2014b; Homma et al. 2009; Hong et al. 2010; Lister et al. 2011; Mitsuishi et al. 2012; Niture et al. 2014; Singh et al. 2008; Storr et al. 2013; Yamadori et al. 2012). Indeed, NRF2 is up-regulated in many types of tumors through somatic mutations that block KEAP1-dependent regulation of NRF2 stability (Mitsuishi et al. 2012; Niture et al. 2014; Storr et al. 2013). Targeting NRF2 either by RNA interference or by small molecules inhibited tumor growth and increased efficacy of chemotherapy (Singh et al. 2008) or EGF-driven proliferation (Yamadori et al. 2012) in non-small cell lung cancer models and reduced the proliferation and drug-resistance in human lung cancer cells (Homma et al. 2009) or human pancreatic cancer cells (Arlt et al. 2013; Duong et al. 2014b; Hong et al. 2010; Lister et al. 2011). Additionally in primary murine cell models, oncogenes including K-Ras, B-Raf, and Myc increased the transcription of Nrf2 gene to activate antioxidant and detoxification program preferable for oncogenesis (Kang et al. 2014). Under these conditions, genetic targeting of $\mathrm{K}-\mathrm{Ras}^{\mathrm{G} 12 \mathrm{D}}$-driven $\mathrm{Nrf2}$ impaired in vivo tumorigenesis (Kang et al. 2014). Taken together, genome-wide analysis of NRF2-responsive genes in specific cancer types will give insights on the context-dependent roles of NRF2. In this work we delineated NRF2responsive genes in As-PC1 pancreatic cancer cell lines established from metastatic cancer cell in ascites fluid (Chen et al. 1982).

\section{Materials and methods}

Cell culture and reagents

AsPC-1 cells were obtained from the Korean Cell Line Bank (Seoul, Korea) and maintained in RPMI-1640 media (HyClone, Logan, UT) supplemented with $20 \%$ FBS (Invitrogen, Carlsbad, CA) and $100 \mathrm{U} / \mathrm{ml}$ penicillin/streptomycin (Welgene, Daegu, Korea). The cells were cultured in a humidified $5 \% \mathrm{CO}_{2}$ incubator at $37{ }^{\circ} \mathrm{C}$. The cell viability and cell counting were assessed by the Luna Automated Cell Counter (Logos Biosystems, Gyunggi-do, Korea). Tert-butylhydroquinone (tBHQ) was purchased from Sigma (St. Louis, MO) and stored at $-20{ }^{\circ} \mathrm{C}$ dissolved in DMSO with small aliquots.

\section{siRNA transfection}

For NRF2 knockdown, exponentially proliferating cells were transfected with synthesized control siRNA $\left(5^{\prime}\right.$-gacgagcggcacgugcacauu- $3^{\prime}$ ) or NRF2 specific siRNA (5'-gaguaugagcuggaaaaacuu-3') (Hong et al. 2010), both purchased from Bioneer (Daejeon, Korea) using Lipofectamine 2000 (Invitrogen) according to the manufacturer's protocol.

\section{Cell cycle analysis}

Cell cycle analysis was carried out by propidium iodide staining and laser detection of FL2 signal using FACSCalibur (BD Science, Franklin Lakes, NJ), and the data were analyzed by CellQuest Pro software (BD Science). After treatment ( $72 \mathrm{~h}$ for siRNA and $16 \mathrm{~h}$ for tBHQ treatment respectively), cells were washed with PBS, fixed $70 \%$ ethanol, and stained with propidium iodide solution (20 $\mu \mathrm{g} / \mathrm{ml})$ containing RNaseA $(100 \mu \mathrm{g} / \mathrm{ml})$ after removal of ethanol.

RNA extraction

Total RNA from AsPC-1 cell lines were prepared with the RNeasy Mini kit (Qiagen, Valencia, CA) according to the 

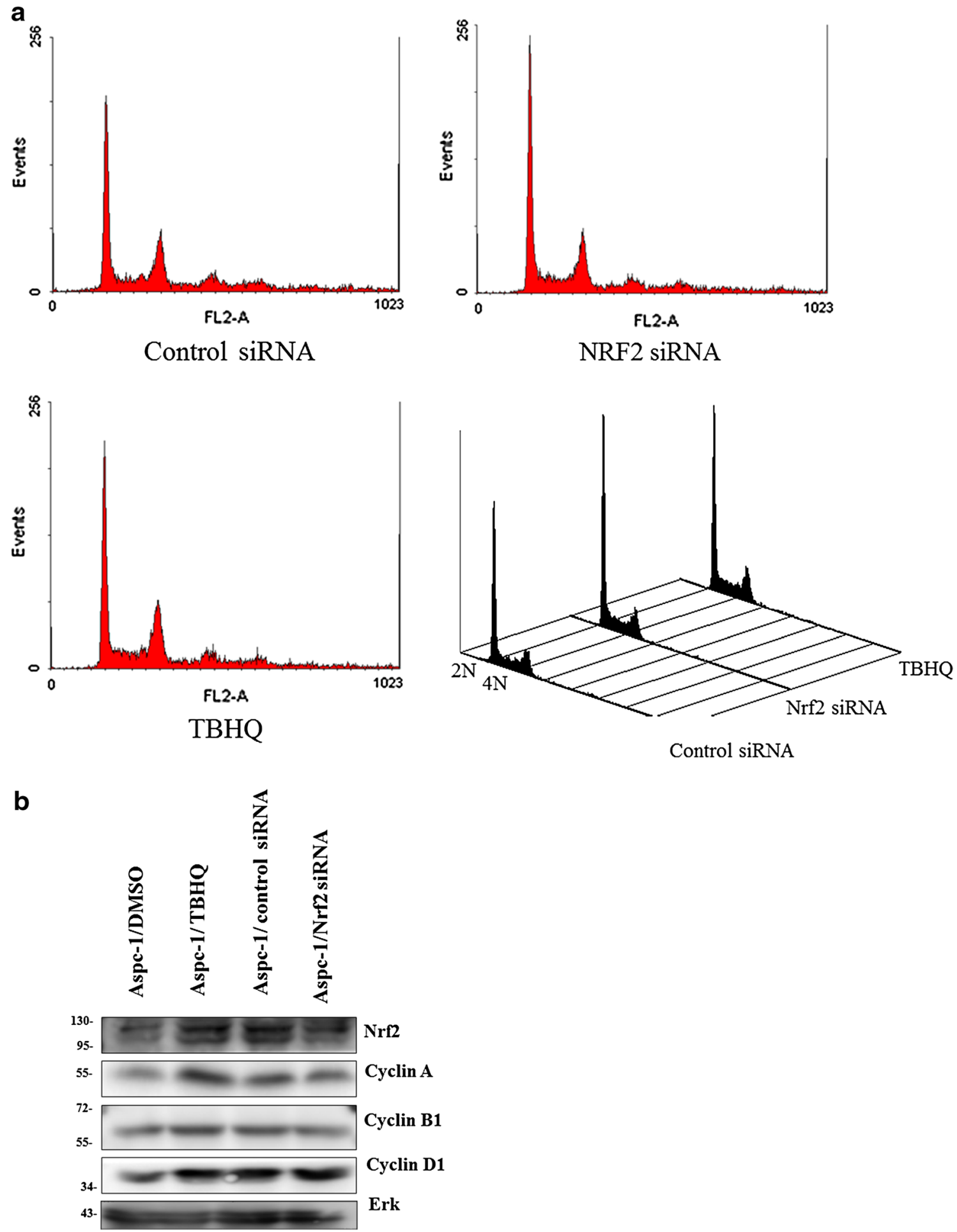

Fig. 1 Cell cycle analysis of NRF2 siRNA-treated or tBHQ-treated AsPC-1 cell line. a A representative image of FL2 histogram of FACS analysis. The figure in the lower right quadrant is combined FACS analysis images with notion of 2 and $4 \mathrm{~N}$ nuclear ploidy. b Immunoblot anaylysis of tBHQ-treated $(100 \mu \mathrm{M} 16 \mathrm{~h})$ or siRNA-treated samples $(72 \mathrm{~h})$. AsPC-1 cells were seeded in 6-well plates and treated

with tBHQ (or DMSO) or NRF2 siRNA (or control siRNA). Cells were harvested and whole cell lysates were prepared, electrophoresed and transferred onto PVDF membranes. Immunoblotting was performed with indicated antibodies and Erk-1 was used as loading control 


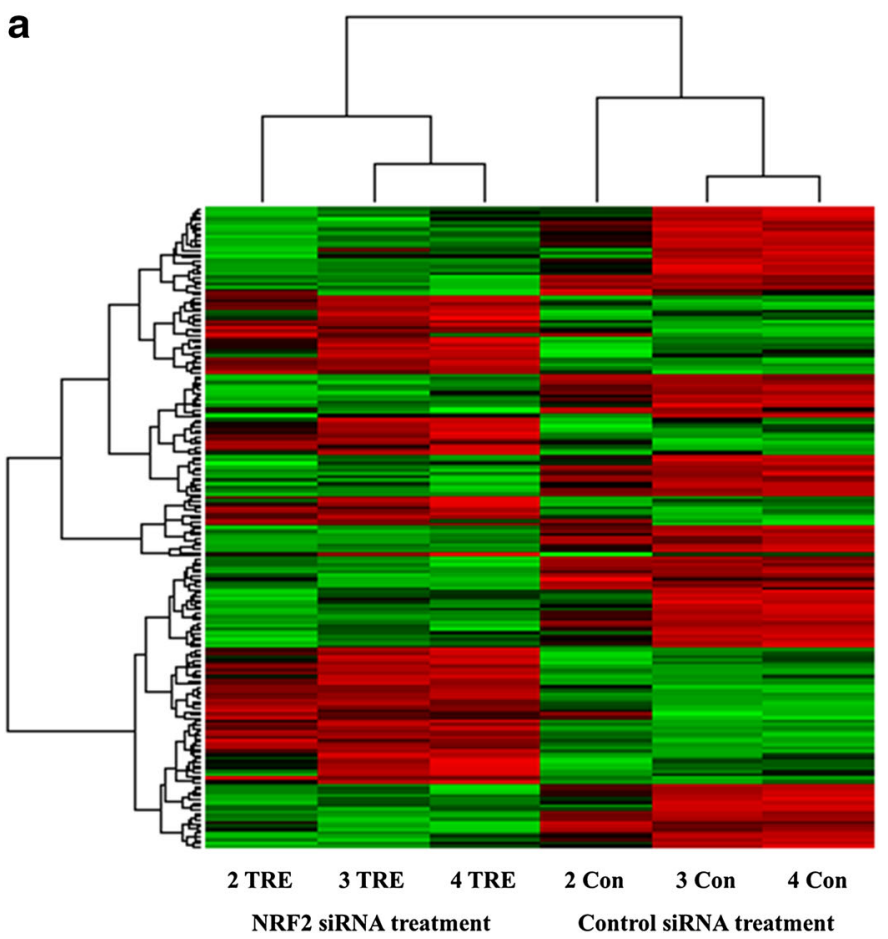

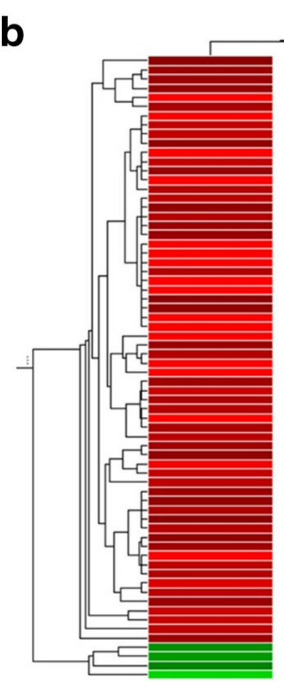

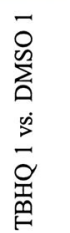

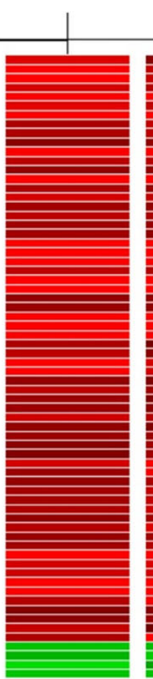

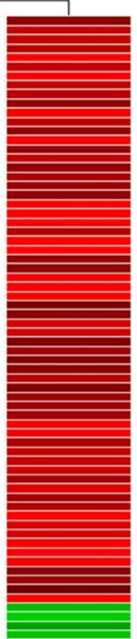

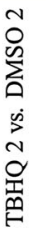

Fig. 2 Hierarchical cluster image of the gene expression profiles of cDNA microarray analysis. a cDNA array of NRF2 siRNA-treated (2TRE, 3 TRE, 4 TRE) and control siRNA-treated sample (2 Con, 3 Con, 4 Con). Each mRNA sample was labeled and hybridized with cDNA array chip (HT 12, Ilumina) and cluster analysis was carried

manufacturer's protocols. The purity and integrity of RNA sample was evaluated by determining the OD260/230 ratio, 28S/18S ratio, peak pattern and electrophoretic migration patterns on Agilent 2100 Bioanalyzer (Agilent Technologies, Palo Alto, CA).

Western blot analysis

After $72 \mathrm{~h}$ of siRNA treatment or $16 \mathrm{~h}$ of tBHQ treatment, AsPC-1 cells were lysed in $10 \mathrm{mM}$ Tris- $\mathrm{HCl}(\mathrm{pH} \mathrm{7.0)}$, $100 \mathrm{mM} \mathrm{NaCl}, 1 \%$ triton X-100, $1 \mathrm{mM}$ DTT, $20 \mu \mathrm{g} / \mathrm{ml}$ aprotinin, $2.5 \mu \mathrm{g} / \mathrm{ml}$ leupeptin, and $0.5 \mathrm{mM}$ PMSF. Lysates were resolved on $10 \%$ sodium dodecyl sulfate-polyacrylamide by gel electrophoresis (SDS-PAGE) and transferred onto $0.45 \mu \mathrm{m}$ pore size Polyvinylidene fluoride (PVDF) membranes (Millipore, Bedford, MA), and immunoblotted with following antibodies: Cyclin B1 antibody (CST\#4135, Cell Signaling Technology, Danvers, MA), Cyclin D1 (CST \#2922, Cell Signaling Technology), NRF2 (sc-103032, Santa Cruz Biotechnology, Santa Cruz, CA), Erk-1 (sc-94, Santa Cruz Biotechnology), Cyclin A (sc-239, Santa Cruz Biotechnology). Horseradish peroxidase (HRP)-conjugated goat anti-rabbit (sc-2004, Santa Cruz Biotechnology) or anti-mouse antibodies (sc-2005, Santa Cruz Biotechnology) were used as secondary antibodies. out. b cDNA array of tBHQ-treated versus DMSO-treated AsPC-1 cells. Two sets of mRNA (tBHQ vs DMSO) with triplicate samples were labeled differently and hybridized. The red color indicated upregulated genes and the green color indicates down-regulated genes

cDNA microarray analysis

The cDNA microarray analysis was carried out with fluorescence labeling of cRNA and hybridization using $4 \times 44 \mathrm{~K}$ Human whole genome microarray (Agilent technologies, Palo Alto, CA) for tBHQ treated cells. For cDNA microarray analysis of NRF2 siRNA treated cell, Ilumina Biochip system (HT-12) was used. For each microarray three RNA samples of independent experiment were used.

Statistical analysis

Data were analyzed by either Student's $t$ test (tBHQ treated sample) or LPE test (siRNA treated sample) (Jain et al. 2003) and the results have been expressed $p$ values and mean values.

\section{Results and discussion}

The AsPC-1 pancreatic cancer cell line, used in this work had been established from metastatic abdominal ascites fluid cells originated from metastatic pancreatic cancer (Chen et al. 1982). It contains well known mutations of pancreatic 
Table 1 List of genes with $(57$ records) with more than two fold increase $(\mathrm{p}<0.05)$ in tBHQ-treated AsPC-1 cells

\begin{tabular}{|c|c|c|c|c|}
\hline Probe ID (Agilent $44 \mathrm{k}$ ) & Gene symbol & Fold change & $\mathrm{p}$ Value & Gene name \\
\hline A_23_P415015 & ATL2 & 10.528 & $5.52 \mathrm{E}-04$ & Atlastin GTPase 2 \\
\hline A_33_P3416588 & RIT2 & 10.341 & $6.05 \mathrm{E}-04$ & Ras-like without CAAX 2 \\
\hline A_23_P83134 & GAS1 $^{\mathbf{M}}$ & 4.752 & $1.13 \mathrm{E}-03$ & Growth arrest-specific 1 \\
\hline A_33_P3257155 & SMAP1 & 4.697 & $4.41 \mathrm{E}-05$ & Small ArfGAP 1 \\
\hline A_24_P129341 & $\operatorname{AKR}_{1 B 10}{ }^{\mathrm{D}}, \mathrm{O}$ & 4.694 & $8.83 \mathrm{E}-04$ & Aldo-keto reductase family 1 , member B 10 \\
\hline A_23_P93641 & $\operatorname{AKR}_{1 B 10}{ }^{\mathrm{D}}, \mathrm{O}$ & 4.652 & $8.91 \mathrm{E}-04$ & Aldo-keto reductase family 1, member B 10 \\
\hline A_33_P3272628 & FCER1G $^{\mathbf{D}}$ & 4.621 & $1.31 \mathrm{E}-04$ & $\begin{array}{l}\text { Fc fragment of IgE, high affinity I, receptor for; } \\
\text { gamma polypeptide }\end{array}$ \\
\hline A_23_P258190 & AKR1B1 $^{\mathrm{D}, \mathrm{O}}$ & 4.588 & $9.03 \mathrm{E}-04$ & Aldo-keto reductase family 1 , member $\mathrm{B} 1$ \\
\hline A_23_P80570 & $\mathbf{A A D A C}^{\mathbf{D}}$ & 4.488 & $9.31 \mathrm{E}-04$ & Arylacetamide deacetylase (esterase) \\
\hline A_33_P3244640 & GRK5 $^{\text {D, M }}$ & 4.433 & $1.06 \mathrm{E}-03$ & $\mathrm{G}$ protein-coupled receptor kinase 5 \\
\hline A_33_P3380992 & $\operatorname{AKR}_{1 B 15}{ }^{D}$ & 4.415 & $9.39 \mathrm{E}-04$ & Aldo-keto reductase family 1 , member B15 \\
\hline A_33_P3304688 & TNAP & 4.272 & $1.06 \mathrm{E}-03$ & TRAFs and NIK-associated protein \\
\hline A_23_P404162 & HDAC9 ${ }^{\mathrm{D}, ~ o, ~ M}$ & 4.176 & $1.07 \mathrm{E}-03$ & Histone deacetylase 9 \\
\hline A_33_P3254751 & LOC100131355 & 3.703 & $1.67 \mathrm{E}-03$ & Hypothetical protein LOC100131355 \\
\hline A_33_P3265394 & WDR74 & 3.071 & $2.51 \mathrm{E}-03$ & WD repeat domain 74 \\
\hline A_23_P257971 & AKR1C1 D, o, M & 3.005 & $1.59 \mathrm{E}-03$ & Aldo-keto reductase family 1 , member $\mathrm{C} 1$ \\
\hline A_23_P323143 & ZNF767 & 2.919 & $1.76 \mathrm{E}-04$ & Zinc finger family member 767 \\
\hline A_33_P3350853 & LOC202781 & 2.885 & $1.74 \mathrm{E}-04$ & Hypothetical LOC202781 \\
\hline A_23_P96623 & OPN1MW & 2.879 & $2.65 \mathrm{E}-03$ & Opsin 1 (cone pigments), medium-wave-sensitive \\
\hline A_33_P3396956 & C1orf172 & 2.874 & $1.87 \mathrm{E}-03$ & Chromosome 1 open reading frame 172 \\
\hline A_23_P67453 & TNNI3 & 2.846 & $2.95 \mathrm{E}-04$ & Troponin I type 3 (cardiac) \\
\hline A_23_P46238 & CELA2A & 2.823 & $2.08 \mathrm{E}-03$ & Chymotrypsin-like elastase family, member $2 \mathrm{~A}$ \\
\hline A_24_P943949 & LRRC8B & 2.775 & $3.48 \mathrm{E}-03$ & Leucine rich repeat containing 8 family, member B \\
\hline A_23_P125042 & ZNF222 & 2.763 & $3.62 \mathrm{E}-03$ & Zinc finger protein 222 \\
\hline A_33_P3268234 & KRT39 & 2.692 & $3.44 \mathrm{E}-03$ & Keratin 39 \\
\hline A_32_P180741 & TNK2 & 2.690 & $3.52 \mathrm{E}-03$ & Tyrosine kinase, non-receptor, 2 \\
\hline A_24_P68908 & LOC344887 & 2.600 & $2.11 \mathrm{E}-03$ & Similar to hCG2041270 \\
\hline A_33_P3314401 & CLDN16 & 2.580 & $3.96 \mathrm{E}-03$ & Claudin 16 \\
\hline A_33_P3365117 & $\operatorname{AKR1C1}^{\mathrm{D}}, \mathbf{O}, \mathrm{M}$ & 2.563 & $4.45 \mathrm{E}-03$ & Aldo-keto reductase family 1 , member $\mathrm{C} 1$ \\
\hline A_24_P152968 & $\operatorname{AKR1C1}^{\mathrm{D}, \mathrm{O}, \mathrm{M}}$ & 2.562 & $2.18 \mathrm{E}-03$ & Aldo-keto reductase family 1 , member $\mathrm{C} 1$ \\
\hline A_23_P63432 & RHBDL2 & 2.509 & $2.89 \mathrm{E}-03$ & Rhomboid, veinlet-like 2 (Drosophila) \\
\hline A_33_P3294277 & $\mathrm{CYP} \mathrm{F3}^{\mathrm{D}}$ & 2.489 & $2.59 \mathrm{E}-03$ & Cytochrome P450, family 4 , subfamily F, polypeptide 3 \\
\hline A_23_P28697 & HAAO & 2.394 & $4.38 \mathrm{E}-03$ & 3-hydroxyanthranilate 3,4-dioxygenase \\
\hline A_24_P678418 & DICER1-AS & 2.378 & $2.74 \mathrm{E}-03$ & Hypothetical locus FLJ45244 \\
\hline A_23_P46222 & TRIM46 & 2.370 & $2.85 \mathrm{E}-03$ & Tripartite motif containing 46 \\
\hline A_33_P3389363 & C19orf54 & 2.364 & $3.17 \mathrm{E}-03$ & Chromosome 19 open reading frame 54 \\
\hline A_23_P502047 & CHRD & 2.345 & $3.99 \mathrm{E}-03$ & Chordin \\
\hline A_23_P50710 & CYP4F2 $2^{\mathrm{D}}$ & 2.340 & $4.52 \mathrm{E}-03$ & Cytochrome $\mathrm{P} 450$, family 4 , subfamily F, polypeptide 2 \\
\hline A_33_P3315239 & ZNF7 & 2.337 & $4.01 \mathrm{E}-03$ & Zinc finger protein 7 \\
\hline A_33_P3336287 & SEC61A2 & 2.322 & $4.20 \mathrm{E}-03$ & Sec61 alpha 2 subunit (S. cerevisiae) \\
\hline A_23_P301521 & KIAA1462 & 2.275 & $6.97 \mathrm{E}-03$ & KIAA1462 \\
\hline A_33_P3420900 & PATE2 & 2.272 & $1.54 \mathrm{E}-03$ & Prostate and testis expressed 2 \\
\hline A_23_P218793 & XPNPEP3 & 2.187 & $3.38 \mathrm{E}-03$ & X-prolyl aminopeptidase (aminopeptidase $\mathrm{P}$ ) 3, putative \\
\hline A_33_P3265714 & C2orf61 & 2.184 & $1.05 \mathrm{E}-02$ & Chromosome 2 open reading frame 61 \\
\hline A_33_P3252381 & PCA3 & 2.167 & $1.36 \mathrm{E}-03$ & Prostate cancer antigen 3 (non-protein coding) \\
\hline A_33_P3378915 & ARHGEF18 & 2.164 & $3.58 \mathrm{E}-03$ & Rho/Rac guanine nucleotide exchange factor (GEF) 18 \\
\hline A_33_P3397520 & KRTAP10-12 & 2.137 & $4.86 \mathrm{E}-03$ & Keratin associated protein $10-12$ \\
\hline A_24_P307135 & TNXB & 2.111 & $7.60 \mathrm{E}-03$ & Tenascin XB \\
\hline
\end{tabular}


Table 1 continued

\begin{tabular}{|c|c|c|c|c|}
\hline Probe ID (Agilent 44 k) & Gene symbol & Fold change & $\mathrm{p}$ Value & Gene name \\
\hline A_33_P3259548 & WDR5B & 2.097 & $4.74 \mathrm{E}-03$ & WD repeat domain $5 \mathrm{~B}$ \\
\hline A_23_P38190 & ORMDL3 & 2.084 & 4.14E-03 & ORM1-like 3 (S. cerevisiae) \\
\hline A_23_P3956 & C1QTNF1 & 2.069 & $3.97 \mathrm{E}-03$ & $\mathrm{C} 1 \mathrm{q}$ and tumor necrosis factor related protein 1 \\
\hline A_33_P3238433 & ALDH3A1 $^{\mathrm{D}, O}$ & 2.063 & $3.96 \mathrm{E}-03$ & Aldehyde dehydrogenase 3 family, memberA 1 \\
\hline A_23_P345678 & FANCD2 ${ }^{\mathrm{D}, \mathrm{O}, \mathrm{M}}$ & 2.046 & $5.27 \mathrm{E}-03$ & Fanconi anemia, complementation group D2 \\
\hline A_33_P3351120 & TXNRD1 $^{\text {D,O }}$ & 2.042 & $4.10 \mathrm{E}-03$ & Thioredoxin reductase 1 \\
\hline A_33_P3258581 & LOC389791 & 2.032 & $5.19 \mathrm{E}-03$ & Hypothetical LOC389791 \\
\hline A_33_P3242623 & SLC7A11 $^{\mathrm{D}, \mathrm{M}}$ & 2.011 & $4.31 \mathrm{E}-03$ & Solute carrier family 7, member 11 \\
\hline A_24_P223163 & NAF1 & 2.006 & $4.47 \mathrm{E}-03$ & Nuclear assembly factor 1 homolog (S. cerevisiae) \\
\hline
\end{tabular}

The fold increased/decreased values are mean of three independent samples. Superscripts were assigned to drug response genes (D), oxidative stress response genes $(\mathrm{O})$ and metastasis $(\mathrm{M})$ related genes according to gene ontology. These gene symbols are presented in bold style

cancer including, KRAS (p.G12D), TP53 (p.C135fsP35), SMAD4 (p.R100T), and other mutations common in cancers as well: COL2A1 (c.915 + 3A > G), FBXW7 (p.R465C), HEY1 (p.I178V), KIF5B (p.Q467K), MLL (p.P3536H), RNF43 (p.S720*) (Deer et al. 2010). The relative expression level of NRF2 between various pancreatic cancer cell lines including immortalized human pancreatic ductal epithelial cell lines (HPDE) using GEO2R analysis with pre-deposited microarray data (Thu et al. 2014) at NCBI Gene Expression Ominbus (http://www.ncbi.nlm.nih.gov/geo/geo2r/?acc= GSE40099\&platform=GPL6480) is presented in supplementary Fig. 1. NRF2 was reported to be increased in pancreatic cancer cell lines and the nuclear level of NRF2 in AsPC- 1 cell line has been reported to be relatively higher than in immortalized pancreatic ductal epithelial cells (Hong et al. 2010; Lister et al. 2011).

An antioxidant tBHQ increases the level of NRF2 protein by stabilization and stimulates the expression of oxidative stress metabolizing genes (Hirose et al. 1993; Li et al. 2005). Prior to cDNA microarray we tested whether tBHQ or NRF2 siRNA treatment can change the cell cycle of AsPC-1 cell line. As shown in Fig. 1a no apparent change in cell cycle distribution was observed along with no accumulation of sub G1 population. Immunoblot analysis also revealed that no apparent change of cell cycle marker proteins including cyclin B1 and cyclin D. The level of NRF2 protein was shown to be increased in tBHQ treated cells and decreased in NRF2 siRNA treated sample (Fig. 1b).

To identify changed genes upon treatment of $100 \mu \mathrm{M}$ tBHQ, we used the Agilent $44 \mathrm{k}$ whole genome cDNA array chip. We also used the Ilumina HT-12 whole genome cDNA array chip for NRF2 siRNA mediated gene expression analysis. Three independent RNA samples were used in these experiments. After removal of marginal or absent signal spots, 20,312 positive spots were obtained from tBHQ-treated sample and 16,423 positive spots were obtained from NRF2 siRNA-treated sample. Hierarchical cluster image of NRF2 siRNA treatment samples reveals that the gene expression pattern of three siRNA-treated sample and three control siRNA-treated samples are adequately clustered (Fig. 2a). Figure $2 \mathrm{~b}$ shows the hierarchical cluster image of cDNA microarray of tBHQ-treated sample indicating three independent samples share concordant RNA expression pattern.

Further statistic tests after normalization of positive spots provide statistically significant 533 array sets from tBHQtreated samples (supplementary Table 1) and 189 array sets from NRF2 siRNA-treated samples (supplementary Table 2). Table 1 shows a list of genes which show more than two fold increase of expression $(p<0.05)$ after treatment of tBHQ (57 genes). Among them AKR1B10, FCERIG, AKRIBI, AKR1B15, AADAC, GRK5, HDAC9, AKR1C1, CYP4F3, CYP4F2, ALDH3A1, FANCD2, TXNRD1 and SLC7A11 are classified as members of drug response genes or oxidative stress response genes according to gene ontology (Table 1). The lists of genes decreased by tBHQ treatment are listed in Table 2. Four genes classified as drug response or oxidative stress response genes were identified: PDE7A, TGM1, CYTH1 and EPS15. The list of top 50 genes which were decreased by NRF2 siRNA treatment are presented in Table 3. The listing is arbitrary but these genes showed more than $40 \%$ reduction in expression. The siRNA mediated knockdown of NRF2 significantly reduced the expression of oxidative stress or drug response genes including, AKR1B10, ALDH1A1, HGD, TFF1, GPX2, ALDH3A1, PPP1R1B, AKR1C4, ABCB6, ABCC3, NFE2L2, EPHX1, ASGR1, SLC2A5, LGALS1 and MTR (Table 3). The expression of $N R F 2$ itself was significantly $(\mathrm{p}<0.001$, $50 \%$ reduction) decreased by the treatment of siRNA reflecting the reliable quality control of siRNA treatment. On the contrary to NRF2 siRNA treatment the change of 
Table 2 Top 50 gene records with decreased expression $(\mathrm{p}<0.05)$ in tBHQ-treated AsPC-1 cells

\begin{tabular}{|c|c|c|c|c|}
\hline Probe ID (Agilent 44 k) & Symbol & Fold change & $\mathrm{p}$ Value & Gene name \\
\hline A_23_P337849 & CELF3 & 0.398 & $1.10 \mathrm{E}-02$ & CUGBP, Elav-like family member 3 \\
\hline A_24_P322229 & RASL10B & 0.466 & $7.41 \mathrm{E}-03$ & RAS-like, family 10 , member B \\
\hline A_33_P3213512 & COQ5 & 0.468 & $1.24 \mathrm{E}-02$ & Coenzyme Q5 homolog, methyltransferase (S. cerevisiae) \\
\hline A_23_P60627 & $\operatorname{ALOX15B}^{\mathrm{M}}$ & 0.475 & $1.30 \mathrm{E}-02$ & Arachidonate 15-lipoxygenase, type B \\
\hline A_33_P3356004 & UCKL1-AS1 & 0.542 & $3.18 \mathrm{E}-02$ & UCKL1 antisense RNA 1 (non-protein coding) \\
\hline A_33_P3247678 & LOC100130876 & 0.550 & $7.40 \mathrm{E}-03$ & Uncharacterized LOC100130876 \\
\hline A_33_P3245679 & LOC100129940 & 0.554 & $2.98 \mathrm{E}-02$ & Uncharacterized LOC100129940 \\
\hline A_23_P146325 & ASAP1-IT1 & 0.566 & $9.59 \mathrm{E}-03$ & ASAP1 intronic Transcript 1 (non-protein coding) \\
\hline A_32_P110016 & LOC727869 & 0.567 & $3.94 \mathrm{E}-02$ & Uncharacterized LOC727869 \\
\hline A_23_P59988 & SLC35G5 & 0.567 & $2.72 \mathrm{E}-02$ & Solute carrier family 35 , member G5 \\
\hline A_33_P3281363 & TRIP12 & 0.573 & $1.24 \mathrm{E}-02$ & Thyroid hormone receptor interactor 12 \\
\hline A_23_P114445 & MAGEE1 & 0.577 & $1.23 \mathrm{E}-02$ & Melanoma antigen family E, 1 \\
\hline A_24_P360529 & PDE7A $^{\mathbf{D}}$ & 0.589 & $3.23 \mathrm{E}-02$ & Phosphodiesterase 7A \\
\hline A_23_P18055 & C3orf51 & 0.597 & $1.85 \mathrm{E}-02$ & Chromosome 3 open reading frame 51 \\
\hline A_33_P3544880 & LOC142937 & 0.622 & $1.05 \mathrm{E}-02$ & Uncharacterized protein $\mathrm{BC} 008131$ \\
\hline A_33_P3576797 & LOC158863 & 0.622 & $1.17 \mathrm{E}-02$ & Uncharacterized LOC158863 \\
\hline A_24_P314597 & KIAA0319L & 0.631 & $1.73 \mathrm{E}-02$ & KIAA0319-like \\
\hline A_33_P3272399 & LOC645427 & 0.632 & $2.14 \mathrm{E}-02$ & Uncharacterized LOC645427 \\
\hline A_33_P3256500 & ATXN2 & 0.636 & $2.07 \mathrm{E}-02$ & Ataxin 2 \\
\hline A_33_P3248265 & LTB & 0.647 & $2.48 \mathrm{E}-02$ & Lymphotoxin beta (TNF superfamily, member 3) \\
\hline A_33_P3522511 & KIAA0485 & 0.649 & $3.41 \mathrm{E}-02$ & Uncharacterized LOC57235 \\
\hline A_33_P3319134 & LOC100506191 & 0.649 & $3.60 \mathrm{E}-02$ & Uncharacterized protein LOC100506191 \\
\hline A_24_P693321 & LOC100190986 & 0.649 & $6.81 \mathrm{E}-03$ & Uncharacterized LOC100190986 \\
\hline A_23_P65618 & TGM1 $^{\mathrm{D}}$ & 0.653 & $2.67 \mathrm{E}-02$ & Transglutaminase 1 \\
\hline A_33_P3249259 & TGM6 & 0.656 & $1.57 \mathrm{E}-02$ & Transglutaminase 6 \\
\hline A_23_P108932 & RPL23AP32 & 0.658 & $4.13 \mathrm{E}-02$ & Ribosomal protein L23a pseudogene 32 \\
\hline A_33_P3333777 & LOC100129387 & 0.661 & $3.27 \mathrm{E}-02$ & Uncharacterized LOC100129387 \\
\hline A_23_P326142 & C7orf54 & 0.663 & $3.05 \mathrm{E}-02$ & Chromosome 7 open reading frame 54 \\
\hline A_33_P3335840 & WDR33 & 0.666 & $3.53 \mathrm{E}-02$ & WD repeat domain 33 \\
\hline A_33_P3324137 & PRO0628 & 0.668 & $1.90 \mathrm{E}-02$ & Uncharacterized LOC29053 \\
\hline A_33_P3393010 & PKDCC & 0.669 & $2.08 \mathrm{E}-02$ & $\begin{array}{l}\text { Protein kinase domain containing, cytoplasmic } \\
\text { homolog (mouse) }\end{array}$ \\
\hline A_33_P3321372 & CNTNAP3 & 0.673 & $1.20 \mathrm{E}-02$ & Contactin associated protein-like 3 \\
\hline A_33_P3250018 & $\mathrm{HCFC} 2$ & 0.673 & $4.56 \mathrm{E}-02$ & Host cell factor $\mathrm{C} 2$ \\
\hline A_33_P3762913 & LOC100216546 & 0.677 & $3.29 \mathrm{E}-02$ & uncharacterized LOC100216546 \\
\hline A_33_P3223990 & TPM3 & 0.680 & $3.66 \mathrm{E}-02$ & Tropomyosin 3 \\
\hline A_33_P3503937 & LOC284581 & 0.683 & $1.31 \mathrm{E}-02$ & Uncharacterized LOC284581 \\
\hline A_33_P3357382 & POGZ & 0.685 & $1.94 \mathrm{E}-02$ & Pogo transposable element with ZNF domain \\
\hline A_33_P3276913 & TTC3 & 0.685 & $3.02 \mathrm{E}-02$ & Tetratricopeptide repeat domain 3 \\
\hline A_33_P3363091 & VAC14 & 0.685 & $2.87 \mathrm{E}-02$ & Vac14 homolog (S. cerevisiae) \\
\hline A_33_P3356525 & FLJ45482 & 0.686 & $1.22 \mathrm{E}-02$ & Uncharacterized LOC645566 \\
\hline A_33_P3310751 & LOC100132249 & 0.690 & $4.21 \mathrm{E}-02$ & Uncharacterized LOC100132249 \\
\hline A_33_P3345743 & PFN1P2 & 0.691 & $2.36 \mathrm{E}-02$ & Profilin 1 pseudogene 2 \\
\hline A_23_P6561 & EBLN2 & 0.692 & $1.29 \mathrm{E}-02$ & Endogenous Bornavirus-like nucleoprotein 2 \\
\hline A_23_P59613 & FZD9 $^{M}$ & 0.692 & $1.63 \mathrm{E}-02$ & Frizzled family receptor 9 \\
\hline A_33_P3397795 & C14orf135 & 0.694 & $1.31 \mathrm{E}-02$ & Chromosome 14 open reading frame 135 \\
\hline A_33_P3304533 & RNF207 & 0.696 & $2.21 \mathrm{E}-02$ & Ring finger protein 207 \\
\hline A_33_P3380405 & CYTH1 $^{\mathrm{D}}$ & 0.699 & $1.98 \mathrm{E}-02$ & Cytohesin 1 \\
\hline A_33_P3538279 & PRO2852 & 0.699 & $2.61 \mathrm{E}-02$ & Uncharacterized protein PRO2852 \\
\hline
\end{tabular}


Table 2 continued

\begin{tabular}{lllll}
\hline Probe ID (Agilent 44 k) & Symbol & Fold change & p Value & Gene name \\
\hline A_23_P60793 & ASMTL-AS1 & 0.703 & 3.95E-02 & ASMTL antisense RNA 1 (non-protein coding) \\
A_33_P3371752 & EPS15 $^{\text {D, M }}$ & 0.704 & $1.52 \mathrm{E}-02$ & Epidermal growth factor receptor pathway substrate 15 \\
A_33_P3355371 & TTC9C & 0.704 & 3.17E-02 & Tetratricopeptide repeat domain 9C \\
\hline
\end{tabular}

The fold increased/decreased values are mean of three independent samples. Superscripts were assigned to drug response genes (D), oxidative stress response genes $(\mathrm{O})$ and metastasis $(\mathrm{M})$ related genes according to gene ontology. These gene symbols are presented in bold style

Table 3 Top 50 gene records with decreased expression $(\mathrm{p}<0.05)$ in NRF2 siRNA-treated AsPC-1 cells

\begin{tabular}{|c|c|c|c|c|}
\hline Probe IDIlumina & Symbol & Fold change & p Value (LPE t-test) & Gene name \\
\hline ILMN_1672148 & $\operatorname{AKR}_{1 B 10}{ }^{\mathrm{D}, O}$ & 0.241 & $0.00 \mathrm{E}+00$ & Aldo-keto reductase family 1 , member B10 (aldose reductase)* \\
\hline ILMN_1709348 & ALDH1A1 ${ }^{\mathrm{D}, \mathrm{O}, \mathrm{M}}$ & 0.253 & $0.00 \mathrm{E}+00$ & Aldehyde dehydrogenase 1 family, member A1 \\
\hline ILMN_2096372 & ALDH1A1 ${ }^{\mathrm{D}, \mathrm{O}, \mathrm{M}}$ & 0.358 & $4.86 \mathrm{E}-12$ & Aldehyde dehydrogenase 1 family, member A1 \\
\hline ILMN_2198239 & HGD $^{\circ}$ & 0.393 & $5.28 \mathrm{E}-08$ & Homogentisate 1,2-dioxygenase (homogentisate oxidase) \\
\hline ILMN_1794829 & C6orf117 & 0.410 & $1.82 \mathrm{E}-07$ & Chromosome 6 open reading frame 117 \\
\hline ILMN_1729117 & COL5A2 & 0.418 & $1.54 \mathrm{E}-08$ & Collagen, type $\mathrm{V}$, alpha 2 \\
\hline ILMN_1811387 & TFF3 $^{\mathrm{M}}$ & 0.426 & $0.00 \mathrm{E}+00$ & Trefoil factor 3 (intestinal) \\
\hline ILMN_1781745 & C9orf152 & 0.445 & $1.43 \mathrm{E}-06$ & Chromosome 9 open reading frame 152 \\
\hline ILMN_1722489 & TFF1 $^{\mathrm{D}}, \mathrm{O}, \mathrm{M}$ & 0.445 & $1.24 \mathrm{E}-10$ & Trefoil factor 1 \\
\hline ILMN_1800091 & RARRES1 & 0.465 & $1.40 \mathrm{E}-06$ & Retinoic acid receptor responder (tazarotene induced) 1 \\
\hline ILMN_2133205 & GPX2 $2^{\text {D, o }}$ & 0.469 & $3.59 \mathrm{E}-10$ & Glutathione peroxidase 2 (gastrointestinal) \\
\hline ILMN_1702503 & ALDH3A1 $^{\mathrm{D}, \mathrm{O}}$ & 0.481 & $3.84 \mathrm{E}-06$ & Aldehyde dehydrogenase 3 family, memberA $1 *$ \\
\hline ILMN_2412336 & AKR1C2 & 0.488 & $3.94 \mathrm{E}-05$ & Aldo-keto reductase family 1 , member $\mathrm{C} 2$ \\
\hline ILMN_2304495 & PPP1R1B ${ }^{\mathrm{D}, ~ o}$ & 0.489 & $1.57 \mathrm{E}-05$ & Protein phosphatase 1 , regulatory (inhibitor) subunit $1 \mathrm{~B}$ \\
\hline ILMN_1684873 & ARSD & 0.491 & $5.26 \mathrm{E}-05$ & Arylsulfatase D \\
\hline ILMN_1772951 & ST6GALNAC1 & 0.492 & $1.06 \mathrm{E}-07$ & $\begin{array}{l}\text { ST6 ( } \alpha \text {-N-acetyl-neuraminyl-2,3- } \beta \text {-galactosyl-1, 3)-N- } \\
\text { acetylgalactosaminide } \alpha \text {-2,6-sialyltransferase } 1\end{array}$ \\
\hline ILMN_1687757 & $\operatorname{AKR1C4} 4^{\circ}$ & 0.506 & $1.81 \mathrm{E}-04$ & Aldo-keto reductase family 1 , member $\mathrm{C} 4$ \\
\hline ILMN_2193980 & $\mathbf{A B C B}^{\mathrm{D}}$ & 0.509 & $5.44 \mathrm{E}-06$ & ATP-binding cassette, sub-family B (MDR/TAP), member 6 \\
\hline ILMN_2161330 & SPDEF $^{\mathrm{M}}$ & 0.513 & $2.61 \mathrm{E}-03$ & SAM pointed domain containing ets transcription factor \\
\hline ILMN_1677814 & $\mathbf{A B C C 3}^{\mathrm{D}, \mathrm{O}}$ & 0.518 & $3.96 \mathrm{E}-06$ & ATP-binding cassette, sub-family C (CFTR/MRP), member 3 \\
\hline ILMN_1790909 & NFE2L2 ${ }^{\mathrm{D}, ~} \mathrm{O}$ & 0.519 & $6.27 \mathrm{E}-04$ & Nuclear factor (erythroid-derived 2)-like 2 \\
\hline ILMN_1680652 & SELENBP1 & 0.520 & $3.74 \mathrm{E}-04$ & Selenium binding protein 1 \\
\hline ILMN_1756685 & DEPDC6 & 0.523 & $6.27 \mathrm{E}-04$ & DEP domain containing 6 \\
\hline ILMN_1704353 & IGSF3 & 0.525 & $6.27 \mathrm{E}-04$ & Immunoglobulin superfamily, member 3 \\
\hline ILMN_1743620 & RARRES1 & 0.528 & $1.47 \mathrm{E}-03$ & Retinoic acid receptor responder (tazarotene induced) 1 \\
\hline ILMN_1752932 & MPZL2 & 0.532 & $2.94 \mathrm{E}-03$ & Myelin protein zero-like 2 \\
\hline ILMN_1701025 & EPHX1 $^{\mathrm{D}, ~ O}$ & 0.535 & $4.13 \mathrm{E}-05$ & Epoxide hydrolase 1, microsomal (xenobiotic) \\
\hline ILMN_1680738 & C5orf13 & 0.543 & $6.93 \mathrm{E}-03$ & Chromosome 5 open reading frame 13 \\
\hline ILMN_1653956 & LOC644624 & 0.545 & $6.70 \mathrm{E}-03$ & PREDICTED: hypothetical LOC6446241 \\
\hline ILMN_1769013 & ASGR1 $^{\text {D, }}$ O & 0.545 & $2.13 \mathrm{E}-04$ & Asialoglycoprotein receptor 1 \\
\hline ILMN_1748352 & CTSL2 $^{\mathrm{M}}$ & 0.547 & $3.16 \mathrm{E}-03$ & Cathepsin L2 \\
\hline ILMN_1659984 & MEP1A & 0.550 & $3.94 \mathrm{E}-05$ & Meprin A, alpha (PABA peptide hydrolase) \\
\hline ILMN_1736042 & ME1 & 0.551 & $2.91 \mathrm{E}-03$ & Malic enzyme 1, NADP(+)-dependent, cytosolic \\
\hline ILMN_1779015 & ZNF467 & 0.554 & $1.05 \mathrm{E}-03$ & Zinc finger protein 467 \\
\hline ILMN_1761247 & $\mathbf{P I R}^{\mathbf{M}}$ & 0.561 & $1.83 \mathrm{E}-02$ & Pirin (iron-binding nuclear protein) \\
\hline ILMN_2255579 & RAB37 & 0.565 & $6.27 \mathrm{E}-04$ & RAB37, member RAS oncogene family \\
\hline ILMN_1726114 & SLC45A3 & 0.566 & $1.96 \mathrm{E}-06$ & Solute carrier family 45 , member 3 \\
\hline
\end{tabular}


Table 3 continued

\begin{tabular}{|c|c|c|c|c|}
\hline Probe IDIlumina & Symbol & Fold change & $\mathrm{p}$ Value (LPE t-test) & Gene name \\
\hline ILMN_1671337 & SLC2A5 ${ }^{\mathrm{D}, \mathrm{O}}$ & 0.566 & $6.19 \mathrm{E}-03$ & $\begin{array}{l}\text { Solute carrier family } 2 \text { (facilitated glc/fruc transporter), } \\
\text { member } 5\end{array}$ \\
\hline ILMN_2278335 & LOC441282 & 0.567 & $4.28 \mathrm{E}-04$ & Similar to aldo-keto reductase family 1 , member B10 \\
\hline ILMN_1712305 & CYBRD1 & 0.572 & $6.27 \mathrm{E}-04$ & Cytochrome $\mathrm{b}$ reductase 1 \\
\hline ILMN_2383383 & $\mathbf{P I R}^{\mathbf{M}}$ & 0.576 & $1.74 \mathrm{E}-02$ & Pirin (iron-binding nuclear protein) \\
\hline ILMN_1657547 & CCDC34 & 0.578 & $2.33 \mathrm{E}-04$ & Coiled-coil domain containing 34 \\
\hline ILMN_1678692 & MPRIP & 0.579 & $9.67 \mathrm{E}-03$ & Myosin phosphatase Rho interacting protein \\
\hline ILMN_1723978 & LGALS1 $^{\mathrm{D},} \mathbf{O}, \mathrm{M}$ & 0.579 & $5.76 \mathrm{E}-03$ & Lectin, galactoside-binding, soluble, 1 \\
\hline ILMN_2087692 & CYBRD1 & 0.581 & $1.45 \mathrm{E}-03$ & Cytochrome $\mathrm{b}$ reductase 1 \\
\hline ILMN_1802100 & ADAM28 & 0.587 & $3.29 \mathrm{E}-02$ & ADAM metallopeptidase domain 28 \\
\hline ILMN_1761733 & HLA-DMB & 0.587 & $7.93 \mathrm{E}-03$ & Major histocompatibility complex, class II, DM beta \\
\hline ILMN_1695397 & LOC644151 & 0.588 & $1.64 \mathrm{E}-03$ & PREDICTED: similar to calpain 8 (LOC644151) \\
\hline ILMN_1670801 & MTR $^{\mathrm{D}, \mathrm{O}}$ & 0.591 & $3.80 \mathrm{E}-02$ & 5-methyltetrahydrofolate-homocysteine methyltransferase \\
\hline ILMN_1699728 & BTD & 0.591 & $1.74 \mathrm{E}-02$ & Homo sapiens biotinidase \\
\hline
\end{tabular}

The fold changes are mean of three independent samples. Superscripts were assigned to drug response genes (D), oxidative stress response genes (O) and metastasis (M) related genes according to gene ontology. These gene symbols are presented in bold style

Table 4 Top 50 gene records with increased expression $(\mathrm{p}<0.05)$ in NRF2 siRNA-treated AsPC-1 cells

\begin{tabular}{|c|c|c|c|c|}
\hline Probe ID Ilumina & Symbol & Fold change & $\mathrm{p}$ Value (LPE t-test) & Gene name \\
\hline ILMN_1796094 & $\mathrm{CD36}^{\mathrm{D}, \mathrm{O}, \mathrm{M}}$ & 4.476 & $4.78 \mathrm{E}-25$ & CD36 molecule (thrombospondin receptor) \\
\hline ILMN_1784863 & $\mathrm{CD36}^{\mathrm{D}, \mathrm{O}, \mathrm{M}}$ & 3.416 & $4.13 \mathrm{E}-13$ & CD36 molecule (thrombospondin receptor) \\
\hline ILMN_1656501 & DUSP5 & 2.664 & $1.24 \mathrm{E}-08$ & Dual specificity phosphatase 5 \\
\hline ILMN_1679262 & DPYSL3 $^{\mathrm{M}}$ & 2.389 & $7.67 \mathrm{E}-11$ & Dihydropyrimidinase-like 3 \\
\hline ILMN_1693789 & $\mathbf{A L P P}^{\mathbf{D}, \mathbf{O}}$ & 2.296 & $1.82 \mathrm{E}-07$ & Alkaline phosphatase, placental (Regan isozyme) \\
\hline ILMN_1700144 & ITGA10 & 2.241 & $7.76 \mathrm{E}-06$ & Integrin, alpha 10 \\
\hline ILMN_1787691 & CITED4 & 2.157 & $5.80 \mathrm{E}-06$ & $\begin{array}{l}\text { Cbp/p300-interacting transactivator, with } \\
\text { Glu/Asp-rich carboxy-terminal domain, } 4\end{array}$ \\
\hline ILMN_2108735 & EEF1A2 & 2.094 & $6.43 \mathrm{E}-03$ & Eukaryotic translation elongation factor 1 alpha 2 \\
\hline ILMN_1813386 & CORO6 & 2.073 & $4.73 \mathrm{E}-05$ & Coronin 6 \\
\hline ILMN_2368530 & IL32 $^{\mathrm{M}}$ & 2.042 & $1.06 \mathrm{E}-07$ & Interleukin 32 \\
\hline ILMN_1776861 & HAP1 & 2.039 & $2.25 \mathrm{E}-04$ & Huntingtin-associated protein 1 \\
\hline ILMN_2317581 & SHANK3 & 2.023 & $2.48 \mathrm{E}-05$ & SH3 and multiple ankyrin repeat domains 3 \\
\hline ILMN_2317580 & SHANK3 & 1.950 & $1.28 \mathrm{E}-03$ & SH3 and multiple ankyrin repeat domains 3 \\
\hline ILMN_2049417 & TMEM86B & 1.920 & $8.22 \mathrm{E}-04$ & Transmembrane protein $86 \mathrm{~B}$ \\
\hline ILMN_1778010 & IL 32 $^{\mathrm{M}}$ & 1.919 & $2.26 \mathrm{E}-04$ & Interleukin 32 \\
\hline ILMN_1697460 & REEP6 & 1.915 & $4.15 \mathrm{E}-03$ & Receptor accessory protein 6 \\
\hline ILMN_1710553 & TMEM151A & 1.900 & $2.61 \mathrm{E}-03$ & Transmembrane protein $151 \mathrm{~A}$ \\
\hline ILMN_1678086 & CCDC74A & 1.894 & $2.68 \mathrm{E}-03$ & Coiled-coil domain containing 74A \\
\hline ILMN_1778401 & HLA-B ${ }^{\mathrm{D}, \mathrm{O}, \mathrm{M}}$ & 1.878 & $8.82 \mathrm{E}-05$ & Major histocompatibility complex, class I, B \\
\hline ILMN_1709659 & TMEM151A & 1.868 & $1.74 \mathrm{E}-02$ & Transmembrane protein $151 \mathrm{~A}$ \\
\hline ILMN_1734707 & CHST13 & 1.857 & $3.42 \mathrm{E}-03$ & Carbohydrate (chondroitin 4) sulfotransferase 13 \\
\hline ILMN_1794501 & $\mathbf{H A S 3}^{\mathrm{M}}$ & 1.840 & $1.28 \mathrm{E}-03$ & Hyaluronan synthase 3 \\
\hline ILMN_1674580 & TRIM36 & 1.834 & $1.67 \mathrm{E}-03$ & Tripartite motif-containing 36 \\
\hline ILMN_1761912 & MGAT1 & 1.824 & $1.29 \mathrm{E}-02$ & $\begin{array}{l}\text { Mannosyl (alpha-1,3-)-glycoprotein beta- } \\
\text { 1,2-N-acetylglucosaminyl transferase }\end{array}$ \\
\hline ILMN_1679267 & TGM2 $^{\mathrm{D}, \mathrm{O}, \mathrm{M}}$ & 1.818 & $1.28 \mathrm{E}-03$ & Transglutaminase 2 \\
\hline ILMN_2136971 & FABP3 $^{\mathrm{D},} \mathbf{O}, \mathbf{M}$ & 1.815 & $5.45 \mathrm{E}-03$ & Fatty acid binding protein 3 , muscle and heart \\
\hline
\end{tabular}


Table 4 continued

\begin{tabular}{|c|c|c|c|c|}
\hline Probe ID Ilumina & Symbol & Fold change & $\mathrm{p}$ Value (LPE t-test) & Gene name \\
\hline ILMN_2077680 & CLDND2 & 1.814 & $2.15 \mathrm{E}-03$ & Claudin domain containing 2 \\
\hline ILMN_1669362 & IGFBP6 & 1.811 & $3.15 \mathrm{E}-06$ & Insulin-like growth factor binding protein 6 \\
\hline ILMN_2361737 & TRIM36 & 1.809 & $2.94 \mathrm{E}-03$ & Tripartite motif-containing 36 \\
\hline ILMN_1805842 & FHL1 & 1.796 & $1.82 \mathrm{E}-03$ & Four and a half LIM domains 1 \\
\hline ILMN_2390853 & CTSH $^{\mathrm{D}, \mathrm{O}}$ & 1.780 & $2.68 \mathrm{E}-03$ & Cathepsin $\mathrm{H}$ \\
\hline ILMN_1676712 & LOC645553 & 1.778 & $1.28 \mathrm{E}-03$ & PREDICTED: hypothetical LOC645553 \\
\hline ILMN_2171384 & $\operatorname{CXCL5}^{\mathrm{M}}$ & 1.766 & $1.17 \mathrm{E}-02$ & Chemokine (C-X-C motif) ligand 5 \\
\hline ILMN_1780057 & RENBP & 1.764 & $6.43 \mathrm{E}-03$ & Renin binding protein \\
\hline ILMN_2188264 & CYR61 $^{\text {O, M }}$ & 1.759 & $5.85 \mathrm{E}-03$ & Cysteine-rich, angiogenic inducer, 61 \\
\hline ILMN_1782305 & NR4A2 $2^{\mathrm{O}, \mathrm{M}}$ & 1.744 & $9.73 \mathrm{E}-03$ & Nuclear receptor subfamily 4 , group A, member 2 \\
\hline ILMN_1792538 & CD7 & 1.740 & $3.63 \mathrm{E}-02$ & CD7 molecule \\
\hline ILMN_1705814 & KRT80 & 1.738 & $9.51 \mathrm{E}-03$ & Keratin 80 \\
\hline ILMN_1721876 & TIMP2 ${ }^{\text {O, M }}$ & 1.733 & $3.53 \mathrm{E}-02$ & TIMP metallopeptidase inhibitor 2 \\
\hline ILMN_1655915 & MMP11 $^{\text {M }}$ & 1.725 & $2.02 \mathrm{E}-02$ & Matrix metallopeptidase 11 (stromelysin 3) \\
\hline ILMN_1656361 & LOC201175 & 1.722 & $1.43 \mathrm{E}-02$ & Hypothetical protein LOC201175 \\
\hline ILMN_1785646 & PMP22 & 1.720 & $4.71 \mathrm{E}-02$ & Peripheral myelin protein 22 \\
\hline ILMN_1748844 & CNKSR3 & 1.713 & $1.29 \mathrm{E}-02$ & CNKSR family member 3 \\
\hline ILMN_2360415 & PRNP $^{O}$ & 1.713 & $2.15 \mathrm{E}-02$ & Prion protein $(\mathrm{PRNP}) 2$ \\
\hline ILMN_1814296 & TRPM6 & 1.711 & $2.15 \mathrm{E}-03$ & $\begin{array}{l}\text { Transient receptor potential cation channel, subfamily } \\
\text { M, member } 6\end{array}$ \\
\hline ILMN_1667295 & VASN & 1.706 & $1.84 \mathrm{E}-02$ & Vasorin \\
\hline ILMN_1727466 & KCNMB4 & 1.700 & $5.76 \mathrm{E}-03$ & $\begin{array}{l}\text { Potassium large conductance calcium-activated channel, } \\
\text { subfamily M, beta member } 4\end{array}$ \\
\hline ILMN_2405009 & NBL1 & 1.695 & $2.38 \mathrm{E}-02$ & Neuroblastoma, suppression of tumorigenicity 1 \\
\hline ILMN_1801246 & IFITM1 & 1.694 & $6.27 \mathrm{E}-04$ & Interferon induced transmembrane protein $1(9-27)$ \\
\hline ILMN_2339955 & NR4A2 $2^{\text {O, M }}$ & 1.688 & $3.79 \mathrm{E}-02$ & Nuclear receptor subfamily 4 , group A, member 2 \\
\hline
\end{tabular}

The fold changes are mean of three independent samples. Superscripts were assigned to drug response genes (D), oxidative stress response genes (O) and metastasis (M) related genes according to gene ontology. These gene symbols are presented in bold style

$N R F 2$ expression by the tBHQ treatment was not significant (data not shown) since tBHQ stabilized NRF2 protein but had no effect on the mRNA level of NRF2. The array results of increased genes under the NRF2 activated status (tBHQ treatment) and decreased genes by the NRF2 siRNA treatment seem to be coincide. We listed top 50 gene records with increased expression upon NRF2 siRNA treatment in Table 4. Ten genes classified as drug response or oxidative stress response genes were identified as increasing genes in NRF2 siRNA treatment: CD36, ALPP, HLA-B, TGM2, FABP3, CTSH, CYR61, TIMP2, PRNP and NR4A2. We also analyzed metastasis related genes in Tables 1, 2, 3 and 4.

In the cDNA array data of tBHQ-treated cells and NRF2 siRNA-treated samples, total 18 overlapping genes could be obtained with statistical significance $(\mathrm{p}<0.05)$ (Table 5). Unexceptionally 17 genes with increased mRNA expression under the $\mathrm{tBHQ}$ treatment showed decreased expression by NRF2 siRNA treatment. The metastasis genes whose relationship with $\mathrm{NRF} 2$ was reported previously are as follows: AKR1B10 (Agyeman et al. 2012; Nishinaka et al. 2011), ALDH3Al (Agyeman et al. 2012), TXNRDl (Sakurai et al. 2005), AKRIC4 (Ebert et al. 2011), ALDHIAl (Duong et al. 2014a), PIR (Hubner et al. 2009), GPX2 (Banning et al. 2005), UGDH (Loignon et al. 2009), SRXN1 (Soriano et al. 2008), ME1 (Thimmulappa et al. 2002), ABCB6 (Campbell et al. 2013), EPHX1 (Su et al. 2014), NQO1 (Agyeman et al. 2012; Loignon et al. 2009; Thimmulappa et al. 2002), and $A B C C 3$ (Adachi et al. 2007). Interestingly, we identified three new genes including $A L D H 3 A 2, A S P H$, and KISS1 as NRF2-responsive genes in this study. To date no study has been reported the relationship of NRF2 with ALDH3A2, ASPH, and KISS1. KISS1 is a protein with 145 amino acid residues and its role is known as an inhibitor of metastasis (Ji et al. 2013). Overexpression KISS1 inhibits metastatic colony formation in ovarian cancer cell lines (Jiang et al. 2005). However, the role of KISS1 in pancreatic 
Table 5 List of statistically significant overlapping genes between two microarray data (tHBQ mediated activation of NRF2 and siRNA mediated depletion of NRF2)

\begin{tabular}{|c|c|c|c|c|c|c|c|}
\hline Symbol & Probe ID agilent & $\begin{array}{l}\text { Probe ID } \\
\text { Ilumina } \\
\text { (ILMN_) }\end{array}$ & $\begin{array}{l}\text { Fold } \\
\text { change } \\
\text { (TBHQ) }\end{array}$ & $\mathrm{p}$ Value & $\begin{array}{l}\text { Fold } \\
\text { change } \\
\text { (SiRNA) }\end{array}$ & $\begin{array}{l}\mathrm{p} \text { Value } \\
\text { (LPE t } \\
\text { test) }\end{array}$ & Gene name \\
\hline AKR1B10 & A_24_P129341 & 1672148 & 4.694 & $8.83 \mathrm{E}-04$ & 0.241 & $0.00 \mathrm{E}+00$ & $\begin{array}{l}\text { Aldo-keto reductase family } 1, \text { member } \mathrm{B} 10 \\
\text { (aldose reductase) }\end{array}$ \\
\hline ALDH3A1 $^{\text {D, } O}$ & A_33_P3238433 & 1702503 & 2.063 & $3.96 \mathrm{E}-03$ & 0.481 & $3.84 \mathrm{E}-06$ & $\begin{array}{l}\text { Aldehyde dehydrogenase } 3 \text { family, member } \\
\text { A1 }\end{array}$ \\
\hline TXNRD1 ${ }^{\mathrm{D}, \mathrm{O}}$ & A_33_P3351120 & 1717056 & 2.042 & $4.10 \mathrm{E}-03$ & 0.631 & $2.46 \mathrm{E}-03$ & Thioredoxin reductase 1 \\
\hline $\mathbf{P I R}^{\mathbf{M}}$ & A_23_P137035 & 1761247 & 1.982 & $4.53 \mathrm{E}-03$ & 0.561 & $1.83 \mathrm{E}-02$ & Pirin (iron-binding nuclear protein) \\
\hline GPX2 $2^{\text {D, }}$ o & A_23_P3038 & 2133205 & 1.971 & $4.64 \mathrm{E}-03$ & 0.469 & $3.59 \mathrm{E}-10$ & Glutathione peroxidase 2 (gastrointestinal) \\
\hline $\mathrm{AKR}_{1 C 4^{\circ}}$ & A_33_P3272291 & 1687757 & 1.900 & $5.30 \mathrm{E}-03$ & 0.506 & $1.81 \mathrm{E}-04$ & $\begin{array}{l}\text { Aldo-keto reductase family } 1 \text {, member C4 } \\
\text { (chlordecone reductase; } 3 \text {-alpha } \\
\text { hydroxysteroid dehydrogenase, type I; } \\
\text { dihydrodiol dehydrogenase } 4 \text { ) }\end{array}$ \\
\hline $\mathbf{U G D H}^{\mathbf{D}, \mathbf{M}}$ & A_33_P3396607 & 1729563 & 1.856 & $5.80 \mathrm{E}-03$ & 0.619 & $4.86 \mathrm{E}-02$ & UDP-glucose 6-dehydrogenase \\
\hline $\operatorname{ALDH1A1}^{\mathrm{D}, \mathrm{O}, \mathrm{M}}$ & A_23_P83098 & 1709348 & 1.826 & $6.21 \mathrm{E}-03$ & 0.253 & $0.00 \mathrm{E}+00$ & $\begin{array}{l}\text { Aldehyde dehydrogenase } 1 \text { family, member } \\
\text { A1 }\end{array}$ \\
\hline SRXN1 $^{\circ}$ & A_23_P320113 & 1804822 & 1.779 & $6.92 \mathrm{E}-03$ & 0.689 & $4.00 \mathrm{E}-02$ & Sulfiredoxin 1 \\
\hline ME1 & A_23_P8196 & 1736042 & 1.771 & $7.33 \mathrm{E}-03$ & 0.551 & $2.91 \mathrm{E}-03$ & $\begin{array}{l}\text { Malic enzyme 1, NADP(+)-dependent, } \\
\text { cytosolic }\end{array}$ \\
\hline $\mathrm{ABCB}^{\mathrm{D}}$ & A_23_P5441 & 2193980 & 1.575 & $1.27 \mathrm{E}-02$ & 0.509 & $5.44 \mathrm{E}-06$ & $\begin{array}{l}\text { ATP-binding cassette, sub-family B (MDR/ } \\
\text { TAP), member } 6\end{array}$ \\
\hline EPHX1 ${ }^{D,}$ o & A_23_P34537 & 1701025 & 1.538 & $1.46 \mathrm{E}-02$ & 0.535 & $4.13 \mathrm{E}-05$ & $\begin{array}{l}\text { Epoxide hydrolase } 1 \text {, microsomal } \\
\text { (xenobiotic) }\end{array}$ \\
\hline HGD $^{\circ}$ & A_23_P250164 & 2198239 & 1.518 & $1.58 \mathrm{E}-02$ & 0.393 & $5.28 \mathrm{E}-08$ & Homogentisate 1,2 -dioxygenase \\
\hline NQO1 $^{\mathrm{D},}, \mathrm{O}, \mathrm{M}$ & A_23_P206661 & 1720282 & 1.496 & $1.72 \mathrm{E}-02$ & 0.659 & $1.65 \mathrm{E}-02$ & $\mathrm{NAD}(\mathrm{P}) \mathrm{H}$ dehydrogenase, quinone 1 \\
\hline $\operatorname{ALDH3A2}^{\mathrm{D}, \mathrm{O}}$ & A_33_P3336617 & 1794825 & 1.463 & $1.99 \mathrm{E}-02$ & 0.618 & $1.60 \mathrm{E}-02$ & $\begin{array}{l}\text { Aldehyde dehydrogenase } 3 \text { family, member } \\
\text { A2 }\end{array}$ \\
\hline ASPH & A_24_P295245 & 2352934 & 1.375 & $3.11 \mathrm{E}-02$ & 0.615 & $2.20 \mathrm{E}-02$ & Aspartate beta-hydroxylase \\
\hline $\mathrm{ABCC}^{\mathrm{D}, ~} \mathrm{O}$ & A_23_P207507 & 1677814 & 1.330 & $4.09 \mathrm{E}-02$ & 0.518 & $3.96 \mathrm{E}-06$ & $\begin{array}{l}\text { ATP-binding cassette, sub-family C (CFTR } \\
\text { MRP), member } 3\end{array}$ \\
\hline KISS1 $^{\mathrm{M}}$ & A_23_P124892 & 1669404 & 0.771 & $4.70 \mathrm{E}-02$ & 1.534 & $3.29 \mathrm{E}-02$ & KiSS-1 metastasis-suppressor \\
\hline
\end{tabular}

The fold change values are mean of three independent samples. Superscripts were assigned to drug response genes (D), oxidative stress response genes $(\mathrm{O})$ and metastasis $(\mathrm{M})$ related genes according to gene ontology. These gene symbols are presented in bold style

cancers has not yet been elucidated. Previously, a report displayed that $N R F 2$ deficient mice showed higher number of pulmonary metastasis than wild-type mice (Satoh et al. 2010). ShRNA mediated knockdown of NRF2 also enhanced cellular plasticity and motility in HepG2 cell (Rachakonda et al. 2010). However, in esophageal squamous cancer cell line NRF2 suppression downregulated the migration and invasion (Shen et al. 2014). Currently, the potential role of NRF2 in regulation of metastasis is under active investigation.

Conflict of interest Authors declare no conflict of interest.

Open Access This article is distributed under the terms of the Creative Commons Attribution License which permits any use, distribution, and reproduction in any medium, provided the original author(s) and the source are credited.

\section{References}

Acharya A, Das I, Chandhok D, Saha T (2010) Redox regulation in cancer: a double-edged sword with therapeutic potential. Oxid Med Cell Longev 3:23-34

Adachi T, Nakagawa H, Chung I, Hagiya Y, Hoshijima K, Noguchi N, Kuo MT, Ishikawa T (2007) Nrf2-dependent and -independent induction of $\mathrm{ABC}$ transporters $\mathrm{ABCC} 1, \mathrm{ABCC} 2$, and ABCG2 in HepG2 cells under oxidative stress. J Exp Ther Oncol 6:335-348

Agyeman AS, Chaerkady R, Shaw PG, Davidson NE, Visvanathan K, Pandey A, Kensler TW (2012) Transcriptomic and proteomic profiling of KEAP1 disrupted and sulforaphane-treated human breast epithelial cells reveals common expression profiles. Breast Cancer Res Treat 132:175-187

Arlt A, Sebens S, Krebs S, Geismann C, Grossmann M, Kruse ML, Schreiber S, Schafer H (2013) Inhibition of the Nrf2 transcription factor by the alkaloid trigonelline renders pancreatic cancer cells more susceptible to apoptosis through decreased proteasomal gene expression and proteasome activity. Oncogene 32:4825-4835 
Banning A, Deubel S, Kluth D, Zhou Z, Brigelius-Flohe R (2005) The GI-GPx gene is a target for Nrf2. Mol Cell Biol 25:4914-4923. doi:10.1128/MCB.25.12.4914-4923.2005

Bryan HK, Olayanju A, Goldring CE, Park BK (2013) The Nrf2 cell defence pathway: keap1-dependent and -independent mechanisms of regulation. Biochem Pharmacol 85:705-717

Camp ND, James RG, Dawson DW, Yan F, Davison JM, Houck SA, Tang X, Zheng N, Major MB, Moon RT (2012) Wilms tumor gene on $\mathrm{X}$ chromosome (WTX) inhibits degradation of NRF2 protein through competitive binding to KEAP1 protein. J Biol Chem 287:6539-6550

Campbell MR, Karaca M, Adamski KN, Chorley BN, Wang X, Bell DA (2013) Novel hematopoietic target genes in the NRF2mediated transcriptional pathway. Oxid Med Cell Longev 2013:120305

Caputo F, Vegliante R, Ghibelli L (2012) Redox modulation of the DNA damage response. Biochem Pharmacol 84:1292-1306

Chen WH, Horoszewicz JS, Leong SS, Shimano T, Penetrante R, Sanders WH, Berjian R, Douglass HO, Martin EW, Chu TM (1982) Human pancreatic adenocarcinoma: in vitro and in vivo morphology of a new tumor line established from ascites. In Vitro Cell Dev Biol Plant 18:24-34

Chen W, Sun Z, Wang XJ, Jiang T, Huang Z, Fang D, Zhang DD (2009) Direct interaction between Nrf2 and p21(Cip1/WAF1) upregulates the Nrf2-mediated antioxidant response. Mol Cell 34:663-673

Chowdhry S, Zhang Y, McMahon M, Sutherland C, Cuadrado A, Hayes JD (2013) Nrf2 is controlled by two distinct beta-TrCP recognition motifs in its Neh6 domain, one of which can be modulated by GSK-3 activity. Oncogene 32:3765-3781

Corcoran A, Cotter TG (2013) Redox regulation of protein kinases. FEBS J 280:1944-1965

Deer EL, Gonzalez-Hernandez J, Coursen JD, Shea JE, Ngatia J, Scaife CL, Firpo MA, Mulvihill SJ (2010) Phenotype and genotype of pancreatic cancer cell lines. Pancreas 39:425-435

DeNicola GM et al (2011) Oncogene-induced Nrf2 transcription promotes ROS detoxification and tumorigenesis. Nature 475:106-109

Duong HQ, Yi YW, Kang HJ, Bae I, Jang YJ, Kwak SJ, Seong YS (2014a) Combination of dasatinib and gemcitabine reduces the ALDH1A1 expression and the proliferation of gemcitabineresistant pancreatic cancer MIA $\mathrm{PaCa}-2$ cells. Int $\mathrm{J}$ Oncol 44:2132-2138

Duong HQ, Yi YW, Kang HJ, Hong YB, Tang W, Wang A, Seong YS, Bae I (2014b) Inhibition of NRF2 by PIK-75 augments sensitivity of pancreatic cancer cells to gemcitabine. Int J Oncol 44:959-969

Ebert B, Kisiela M, Wsol V, Maser E (2011) Proteasome inhibitors MG-132 and bortezomib induce AKR1C1, AKR1C3, AKR1B1, and AKR1B10 in human colon cancer cell lines SW-480 and HT-29. Chem Biol Interact 191:239-249

Finkel T (2011) Signal transduction by reactive oxygen species. J Cell Biol 194:7-15

Gorrini C, Baniasadi PS, Harris IS, Silvester J, Inoue S, Snow B, Joshi PA, Wakeham A, Molyneux SD, Martin B, Bouwman P, Cescon DW, Elia AJ, Winterton-Perks Z, Cruickshank J, Brenner D, Tseng A, Musgrave M, Berman HK, Khokha R, Jonkers J, Mak TW, Gauthier ML (2013) BRCA1 interacts with Nrf2 to regulate antioxidant signaling and cell survival. J Exp Med 210:1529-1544

Hast BE, Goldfarb D, Mulvaney KM, Hast MA, Siesser PF, Yan F, Hayes DN, Major MB (2013) Proteomic analysis of ubiquitin ligase KEAP1 reveals associated proteins that inhibit NRF2 ubiquitination. Cancer Res 73:2199-2210

Hirose M, Yada H, Hakoi K, Takahashi S, Ito N (1993) Modification of carcinogenesis by alpha-tocopherol, t-butylhydroquinone, propyl gallate and butylated hydroxytoluene in a rat multi-organ carcinogenesis model. Carcinogenesis 14:2359-2364
Homma S, Ishii Y, Morishima Y, Yamadori T, Matsuno Y, Haraguchi N, Kikuchi N, Satoh H, Sakamoto T, Hizawa N, Itoh K, Yamamoto M (2009) Nrf2 enhances cell proliferation and resistance to anticancer drugs in human lung cancer. Clin Cancer Res 15:3423-3432

Hong YB, Kang HJ, Kwon SY, Kim HJ, Kwon KY, Cho CH, Lee JM, Kallakury BV, Bae I (2010) Nuclear factor (erythroid-derived 2)-like 2 regulates drug resistance in pancreatic cancer cells. Pancreas 39:463-472

Hubner RH, Schwartz JD, De Bishnu P, Ferris B, Omberg L, Mezey JG, Hackett NR, Crystal RG (2009) Coordinate control of expression of Nrf2-modulated genes in the human small airway epithelium is highly responsive to cigarette smoking. Mol Med 15:203-219

Jain N, Thatte J, Braciale T, Ley K, O'Connell M, Lee JK (2003) Local-pooled-error test for identifying differentially expressed genes with a small number of replicated microarrays. Bioinformatics 19:1945-1951

Jennings P, Limonciel A, Felice L, Leonard MO (2013) An overview of transcriptional regulation in response to toxicological insult. Arch Toxicol 87:49-72

Ji K, Ye L, Mason MD, Jiang WG (2013) The Kiss-1/Kiss-1R complex as a negative regulator of cell motility and cancer metastasis (Review). Int J Mol Med 32:747-754

Jiang Y, Berk M, Singh LS, Tan H, Yin L, Powell CT, Xu Y (2005) KiSS1 suppresses metastasis in human ovarian cancer via inhibition of protein kinase $\mathrm{C}$ alpha. Clin Exp Metastasis 22:369-376. doi:10.1007/s10585-005-8186-4

Kakehashi A, Wei M, Fukushima S, Wanibuchi H (2013) Oxidative stress in the carcinogenicity of chemical carcinogens. Cancers 5:1332-1354

Kang HJ, Hong YB, Kim HJ, Bae I (2010) CR6-interacting factor 1 (CRIF1) regulates NF-E2-related factor 2 (NRF2) protein stability by proteasome-mediated degradation. J Biol Chem 285:21258-21268

Kang KA, Piao MJ, Kim KC, Kang HK, Chang WY, Park IC, Keum YS, Surh YJ, Hyun JW (2014) Epigenetic modification of Nrf2 in 5-fluorouracil-resistant colon cancer cells: involvement of TET-dependent DNA demethylation. Cell Death Dis 5:e1183. doi:10.1038/cddis.2014.149

Kensler TW, Wakabayashi N (2010) Nrf2: friend or foe for chemoprevention? Carcinogenesis 31:90-99

Komatsu M, Kurokawa H, Waguri S, Taguchi K, Kobayashi A, Ichimura Y, Sou YS, Ueno I, Sakamoto A, Tong KI, Kim M, Nishito Y, Iemura S, Natsume T, Ueno T, Kominami E, Motohashi H, Tanaka K, Yamamoto M (2010) The selective autophagy substrate p62 activates the stress responsive transcription factor Nrf2 through inactivation of Keap1. Nat Cell Biol 12:213-223

Kryston TB, Georgiev AB, Pissis P, Georgakilas AG (2011) Role of oxidative stress and DNA damage in human carcinogenesis. Mutat Res 711:193-201

Li J, Spletter ML, Johnson JA (2005) Dissecting tBHQ induced AREdriven gene expression through long and short oligonucleotide arrays. Physiol Genomics 21:43-58

Lister A, Nedjadi T, Kitteringham NR, Campbell F, Costello E, Lloyd B, Copple IM, Williams S, Owen A, Neoptolemos JP, Goldring CE, Park BK (2011) Nrf2 is overexpressed in pancreatic cancer: implications for cell proliferation and therapy. Mol Cancer 10:37

Loboda A, Was H, Jozkowicz A, Dulak J (2008) Janus face of Nrf2HO-1 axis in cancer-friend in chemoprevention, foe in anticancer therapy. Lung Cancer 60:1-3

Loignon M, Miao W, Hu L, Bier A, Bismar TA, Scrivens PJ, Mann K, Basik M, Bouchard A, Fiset PO, Batist Z, Batist G (2009) Cul3 overexpression depletes Nrf2 in breast cancer and is associated with sensitivity to carcinogens, to oxidative stress, and to chemotherapy. Mol Cancer Ther 8:2432-2440 
Ma Q (2010) Transcriptional responses to oxidative stress: pathological and toxicological implications. Pharmacol Ther 125:376-393

Ma Q (2013) Role of nrf2 in oxidative stress and toxicity. Annu Rev Pharmacol Toxicol 53:401-426

Ma J, Cai H, Wu T, Sobhian B, Huo Y, Alcivar A, Mehta M, Cheung KL, Ganesan S, Kong AN, Zhang DD, Xia B (2012) PALB2 interacts with KEAP1 to promote NRF2 nuclear accumulation and function. Mol Cell Biol 32:1506-1517

Malhotra D, Portales-Casamar E, Singh A, Srivastava S, Arenillas D, Happel C, Shyr C, Wakabayashi N, Kensler TW, Wasserman WW, Biswal S (2010) Global mapping of binding sites for Nrf2 identifies novel targets in cell survival response through ChIP-Seq profiling and network analysis. Nucl Acids Res 38:5718-5734

Mitsuishi Y, Motohashi H, Yamamoto M (2012) The Keap1-Nrf2 system in cancers: stress response and anabolic metabolism. Front Oncol 2:200

Muller T, Hengstermann A (2012) Nrf2: friend and foe in preventing cigarette smoking-dependent lung disease. Chem Res Toxicol 25:1805-1824

Nguyen T, Sherratt PJ, Pickett CB (2003) Regulatory mechanisms controlling gene expression mediated by the antioxidant response element. Annu Rev Pharmacol Toxicol 43:233-260

Nishinaka T, Miura T, Okumura M, Nakao F, Nakamura H, Terada T (2011) Regulation of aldo-keto reductase AKR1B10 gene expression: involvement of transcription factor Nrf2. Chem Biol Interact 191:185-191

Niture SK, Khatri R, Jaiswal AK (2014) Regulation of Nrf2-an update. Free Radic Biol Med 66:36-44

Rachakonda G, Sekhar KR, Jowhar D, Samson PC, Wikswo JP, Beauchamp RD, Datta PK, Freeman ML (2010) Increased cell migration and plasticity in Nrf2-deficient cancer cell lines. Oncogene 29:3703-3714

Rada P, Rojo AI, Chowdhry S, McMahon M, Hayes JD, Cuadrado A (2011) SCF/\{beta\}-TrCP promotes glycogen synthase kinase 3-dependent degradation of the Nrf2 transcription factor in a Keap1-independent manner. Mol Cell Biol 31:1121-1133

Rada P, Rojo AI, Evrard-Todeschi N, Innamorato NG, Cotte A, Jaworski T, Tobon-Velasco JC, Devijver H, Garcia-Mayoral MF, Van Leuven F, Hayes JD, Bertho G, Cuadrado A (2012) Structural and functional characterization of Nrf2 degradation by the glycogen synthase kinase 3/beta-TrCP axis. Mol Cell Biol 32:3486-3499

Ray PD, Huang BW, Tsuji Y (2012) Reactive oxygen species (ROS) homeostasis and redox regulation in cellular signaling. Cell Signal 24:981-990

Saeidnia S, Abdollahi M (2013) Antioxidants: friends or foe in prevention or treatment of cancer: the debate of the century. Toxicol Appl Pharmacol 271:49-63
Sakurai A, Nishimoto M, Himeno S, Imura N, Tsujimoto M, Kunimoto M, Hara S (2005) Transcriptional regulation of thioredoxin reductase 1 expression by cadmium in vascular endothelial cells: role of NF-E2-related factor-2. J Cell Physiol 203:529-537

Satoh H, Moriguchi T, Taguchi K, Takai J, Maher JM, Suzuki T, Winnard P T Jr, Raman V, Ebina M, Nukiwa T, Yamamoto M (2010) Nrf2-deficiency creates a responsive microenvironment for metastasis to the lung. Carcinogenesis 31:1833-1843

Shen H, Yang Y, Xia S, Rao B, Zhang J, Wang J (2014) Blockage of Nrf2 suppresses the migration and invasion of esophageal squamous cell carcinoma cells in hypoxic microenvironment. Dis Esophagus 27:685-692

Singh A, Boldin-Adamsky S, Thimmulappa RK, Rath SK, Ashush H, Coulter J, Blackford A, Goodman SN, Bunz F, Watson WH, Gabrielson E, Feinstein E, Biswal S (2008) RNAi-mediated silencing of nuclear factor erythroid-2-related factor 2 gene expression in non-small cell lung cancer inhibits tumor growth and increases efficacy of chemotherapy. Cancer Res 68:7975-7984

Soriano FX, Leveille F, Papadia S, Higgins LG, Varley J, Baxter P, Hayes JD, Hardingham GE (2008) Induction of sulfiredoxin expression and reduction of peroxiredoxin hyperoxidation by the neuroprotective $\mathrm{Nrf} 2$ activator $3 \mathrm{H}$-1,2-dithiole-3-thione. J Neurochem 107:533-543

Storr SJ, Woolston CM, Zhang Y, Martin SG (2013) Redox environment, free radical, and oxidative DNA damage. Antioxid Redox Signal 18:2399-2408

Su S, Yang X, Omiecinski CJ (2014) Intronic DNA elements regulate Nrf2 chemical responsiveness of the human microsomal epoxide hydrolase gene (EPHX1) through a far upstream alternative promoter. Biochim Biophys Acta 1839:493-505

Thimmulappa RK, Mai KH, Srisuma S, Kensler TW, Yamamoto M, Biswal S (2002) Identification of Nrf2-regulated genes induced by the chemopreventive agent sulforaphane by oligonucleotide microarray. Cancer Res 62:5196-5203

Thu KL, Radulovich N, Becker-Santos DD, Pikor LA, Pusic A, Lockwood WW, Lam WL, Tsao MS (2014) SOX15 is a candidate tumor suppressor in pancreatic cancer with a potential role in Wnt/beta-catenin signaling. Oncogene 33:279-288

Yamadori T, Ishii Y, Homma S, Morishima Y, Kurishima K, Itoh K, Yamamoto M, Minami Y, Noguchi M, Hizawa N (2012) Molecular mechanisms for the regulation of Nrf2-mediated cell proliferation in non-small-cell lung cancers. Oncogene 31:4768-4777 